\title{
Genotypical diversity of HIV clades and central nervous system impairment
}

\author{
Indianara Rotta ${ }^{1,2}$, Sérgio Monteiro de Almeida ${ }^{1,2}$
}

\begin{abstract}
The central nervous system (CNS) and the immune system are considered major target organs for HIV infection. The neurological manifestations directly related to HIV are acute viral meningitis, chronic meningitis, HIV associated dementia, vacuolar myelopathy and involvement of the peripheral nervous system. Changes in diagnosis and clinical management have changed the aspect of HIV infection so that it is no longer a fatal disease, and has become a chronic disease requiring sustained medical management. After HAART the incidence of most opportunistic infections, including those affecting the CNS, has dropped markedly. Some studies suggest that neurological involvement of infected patient occur with different frequency, depending on HIV subtype involved in the infection. Subtype $\mathrm{C}$ may have reduced neuroinvasive capacity, possibly due to its different primary conformation of HIV transactivating regulatory protein (Tat), involved in monocyte chemotaxis. This review focus on physiopathologic aspects of HIV infection in CNS and its correlation with HIV clades.
\end{abstract}

Key words: HIV, AIDS, central nervous system, clades, genotyping, HIV dementia.

\section{Diversidade genotípica dos subtipos de HIV e comprometimento do sistema nervoso central}

\section{RESUMO}

O sistema nervoso central (SNC) e o sistema imunológico são considerados os principais órgãos alvo na infecção pelo HIV. As manifestações neurológicas diretamente relacionadas ao HIV são meningites virais aguda e crônica, demência associada ao HIV, mielopatia vacuolar e envolvimento do sistema nervoso periférico. Mudanças no diagnóstico e sobrevida têm mudado o aspecto da infecção pelo HIV, não mais considerada uma doença fatal e sim crônica. Após HAART, a incidência da maioria das doenças oportunistas, incluindo aquelas que afetam o SNC, reduziu-se significativamente. Alguns estudos sugerem que o envolvimento de pacientes infectados ocorre com frequência diferente, dependendo do subtipo de HIV. O subtipo $\mathrm{C}$ apresenta uma capacidade reduzida de neuroinvasão, possivelmente devido a conformação primária da sua proteína reguladora da transativação (Tat), que perde sua capacidade quimiotáxica. Esta revisão aborda aspectos fisiopatológicos da infecção do HIV no SNC e subtipos de HIV.

Palavras-Chave: HIV, AIDS, sistema nervoso central, subtipos, genotipagem, HIV demência.

\section{Correspondence}

Sérgio Monteiro de Almeida Hospital de Clínicas / UFPR

Seção de Virologia Setor Análises Clínicas Rua Padre Camargo 280 80060-240 Curitiba PR - Brasil E-mail: sergio.ma@pop.com.br

\section{HIV and subtypes}

There is a great diversity of the HIV all around the world, this distribution is highly dynamic. Two types of HIV circulate worldwide: HIV-1 and HIV-2. The commonest and most virulent form is HIV-1, with a prevalence of almost $90 \%$, and the infection is characterized by ge- netic diversity. Thus, HIV-1 accounts for most HIV infections in Brazil ${ }^{1}$. HIV-2 is less easily transmitted, occurring in few countries of western Africa, Europe and in India. This type is less virulent than HIV-1 and the course of the syndrome is less aggressive $^{2}$. HIV-1 and HIV-2 co-infection has been recently identified in several Bra- 
zilian states ${ }^{3}$. Infection by HIV-2 should be ruled out in individuals testing for HIV who come from or travel to West Africa and other areas where HIV-2 is endemic, particularly those who have negative or indeterminate results for HIV-1 Western blot testing or who have atypical banding patterns and/or have clinical signs of HIV infection or unexplained immunosuppression ${ }^{4}$.

Mutation and recombination are the major mechanisms of genetic diversity generation as well as HIV-1 evolution in the pandemic ${ }^{5}$.

HIV has an intrinsic mechanism that ensures rapid viral evolution. Reverse transcriptase forwards mutation rate and produces millions of variants per day ${ }^{6}$.

Phylogenetic analysis shows that early in the $20^{\text {th }}$ century three independent transmission events have occurred, which generated three HIV-1 groups: major (M), outlier $(\mathrm{O})$ and non-M non- $\mathrm{O}(\mathrm{N})$. The $\mathrm{M}$ and $\mathrm{N}$ groups were originated in chimpanzees, but group $\mathrm{O}$ may have originated in gorillas (SIVgor) from Zaire, where the first case of HIV-1 (group M) infection among humans was documented in $1959^{6}$. In 2009, a new HIV lineage, designated group P (putative), was described ${ }^{7}$.

The $\mathrm{M}$ group, which accounts for $90 \%$ of all the infections, is divided into nine subtypes, classified as A, B, C, D, F, G, H, J and $\mathrm{K}^{6}$ (14) (Fig 1) ${ }^{8}$.

HIV-1 subtypes show 70-90\% sequence identity, the groups share less than 70\% sequence identity and types differ around $50 \%$ at the nucleotide level ${ }^{2}$.

HIV-1 is classified into circulating recombinant form (CRF) and unique recombinant form (URF), the result of recombination between subtypes in an individual infected with two distinct subtypes. Around 46 CRFs have been identified so far ${ }^{6}$.

Subtype $C$ is the most prevalent clade circulating around the world. It accounts for more than $52 \%$ of all the infections. It is the most prevalent HIV infection in sub-Saharan Africa, India and China. Subtype B is prevalent in the west Europe, America and Oceania ${ }^{2}$. In Brazil, there is clear predominance of subtype $\mathrm{B}^{9}$.

Data suggest that subtype $C$ is more frequently transmitted than subtype B. Subtype $C$ predominance in actual epidemic might be related to a lower virulence and a greater efficient transmission of this subtype compared to other M subtype groups. Since subtype $C$ is less virulent, this implies in a slower disease progression, longer periods of asymptomatic infection and more opportunities for viral transmission ${ }^{2}$.

In the south-east region of Brazil subtype B is the most common subtype, followed by F1 and BF1 recombinant forms; subtype $C$ is less prevalent. In the centralwest and north-east regions a similar distribution is observed. In the north, the most common subtype is F1 and BF1 recombinants, followed by subtype $B^{9,10}$.

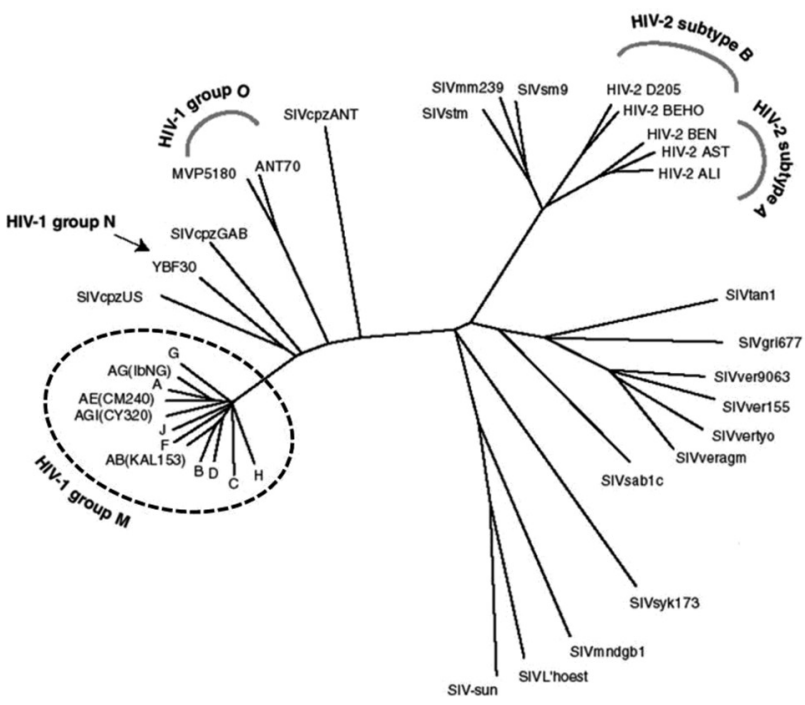

Fig 1. Phylogenetic tree of lentiviruses showing the HIV-1 groups and subgroups and the distance between HIV-1 e HIV-2. Modified from Calef $C$, et al. ${ }^{8}$.

In the south region, a subtype $C$ variant of monophyletic origin has spread, with a prevalence of $30-45 \%$ of infections. Subtype B infections and a minor fraction of subtype $\mathrm{F} 1$ and BF1 recombinants were also observed ${ }^{10}$.

Further studies on the identification of prevalent subtypes in a given population and in risk groups should be carried out to increase knowledge on the illness ${ }^{10}$.

Studies on the dissemination of HIV associated to the understanding of its biology are crucial to guide health policies in the control of viral expansion and in the reduction of AIDS incidence around the world ${ }^{11}$. Detailed molecular studies of all the circulating strains of HIV-1 are crucial to vaccine coverage against all different viral subtypes $^{12}$.

The recognition of these variants is important to the characterization of intra-subtypes or intra-CRF recombinants and superinfections in regions where two or more variants circulate. This recognition may be also important for viral biology studies, susceptibility to immune responses, response and development of resistance to antiretroviral (ARV) drugs, pathogenicity and transmissibility 5 .

Continued monitoring of the genetic composition of the epidemic is needed because of the fast changes in the distribution of different HIV-1 genetic forms, due to the introduction of new strains, expansion of minor variants, local generation and expansion of new recombinant genetic forms $\mathrm{s}^{5}$.

Some studies suggest that neurological involvement of infected patients occurs at different frequencies, depending on the HIV subtype involved in the infection. Subtype C may have reduced neuroinvasive capacity, possibly due to its different primary conformation of 
HIV transactivating regulatory protein (Tat), involved in monocyte chemotaxis ${ }^{13}$.

\section{HIV-related neurological complications}

In the adult brain, only macrophages and microglia are productively infected and HIV does not effectively penetrate or replicate in neurons.

The neurological manifestations directly related to HIV are acute viral meningitis, chronic meningitis, HIVassociated dementia (HAD), vacuolar myelopathy and involvement of the peripheral nervous system ${ }^{2}$.

HIV probably penetrates the central nervous system (CNS) in the initial stages of the infection. In this period, the viral load in peripheral blood is as high as in the final stage of the illness when CNS penetration occurs. Some papers have identified the presence of HIV proteins or intrathecal synthesis of anti-HIV antibodies in the initial stage of the infection ${ }^{14}$.

Around 5 to $10 \%$ of patients have acute viral meningitis at the time of acquisition of the HIV virus or in the seroconversion stage. Concerning the cerebrospinal fluid (CSF) cytology and biochemistry, this acute meningitis is not clinically different from acute meningitis caused by other viruses, as the enterovirus. Some patients, however, have peripheral facial palsy associated to meningitis. As seroconversion progresses at the stage of acute meningitis, the test for anti-HIV antibodies in serum or CSF is negative $e^{15,16}$.

\section{Penetration of the HIV-1 in the CNS}

The penetration of HIV in the CNS through neurons by axonal flow, as it occurs with herpes virus or rabies virus, is less probable because the CD4 receptor, the main receptor that enables HIV to infect the cell, is absent in neurons ${ }^{17}$. Penetration using the hematogenic route is more likely to occur, with free particles in the CNS crossing the microvessels that compose the bloodbrain-barrier (BBB) or the blood CSF barrier (BCB) or through infected cells, such as lymphocytes or monocytes. All these forms of penetration are probably involved, becoming more or less important depending on the infection stage ${ }^{18}$. The penetration through infected monocytes/macrophages, the "Trojan Horse" theory, is currently considered the main form of HIV penetration into the $\mathrm{CNS}^{19}$.

The disrupted BBB during HIV infection allows free particles and infected monocytes to penetrate into the CNS. These cells can penetrate through tight junctions or through capillary endothelial cells, with the latter being more likely to penetrate into the CNS than the former. Moreover, higher levels of matrix metalloproteinases (MMPs) in the CNS have been found. MMPs can weaken the basal membrane facilitating the migration of leuko- cytes across the $\mathrm{BBB}^{20}$. HIV-1 infected monocytes show an increase in adhesion among endothelial and astrocyte cell cultures. Endothelial cells with modified function can increase endothelial adhesion and monocyte infiltration into the CNS, due to alterations in the composition of the proteins of the basal membrane. These alterations are also caused by the production of derivatives of the virus itself or free chemokines, by either infected cells, non-infected cells or by astrocyte infection ${ }^{18,21}$.

\section{Potentially HIV infected CNS cells}

Two types of CNS cells can be infected by HIV: cells derived from monocytes (microglia and macrophages) and astrocytes. These cells differ from other HIV infected cells in some biological aspects, particularly in the way they express the products of the HIV. The cellular surface CD4 receptor and the receptors of chemokines CCR5 and CCR3 are involved in the penetration of the virus into the microglia cells. The microglia develops a productive infection leading to syncytium formation and cell death; however, the possibility of chronic infection also exists.

Astrocytes are predominantly infected by lymphotropic strains, and the mechanism of HIV penetration into the astrocytes remains unknown. It has been clearly shown that astrocytes do not have CD4 receptors on their surface. The chemokine receptors associated to HIV infection are not expressed either; however, some authors suggest that CXCR4 can be expressed following the activation of astrocytes ${ }^{22,23}$.

Another protein, Pag (a protein on astrocytes for gp 120 binding) has been related to astrocyte infection. After one short stage of productive viral infection, the HIV-1 present in astrocytes enters a latent or restrictive stage. Astrocyte infection is not cytopathic. Therefore, the virus can remain in these cells almost indefinitely. In this stage of the infection the virus could escape the action of all antiretroviral drugs currently in use. From time to time, following chemokine stimulation, a productive viral response may occur leading to potential re-infection of the CNS and the peripheral blood ${ }^{18,24}$.

\section{CNS injury}

Since neurons do not have CD4 cell surface receptors, they are not directly infected by HIV. The presence of HIV in the CNS is necessary but not sufficient by itself to develop cognitive impairment ${ }^{25}$. Neuronal injury occurs by indirect mechanisms of neurotoxicity as those caused by virus proteins (gp120, gp 41, tat, nef); macrophages factors, cytokines (TNF- alpha, IL-1, IL-6, GM-CSF, IFN), chemokines (MCP-1, MCP-2, MCP-3, RANTES, MIP-1 $\alpha$, MIP-1 $\beta$ ); neurotrophic factors. HIV proteins can mimic body proteins leading to autoimmu- 
nity (gp 41; antibodies for astrocytes, anti-brain antibodies, anti-ganglioside antibodies). Also, BBB disruption may facilitate the penetration of neurotoxins from systemic infection into the brain ${ }^{17,26,27}$.

Neurotoxicity cannot be induced by a long and continuous exposure to viral proteins. A temporary exposure can trigger a cascade of events that result in neuronal damage. These viral proteins, once available in the extracellular space, can cause neurotoxicity by direct action on the neuronal cell, or else can activate the glial cells allowing the viral proteins to increase its potential neurotoxicity and cause greater damage. Moreover, the viral proteins can act in synergy with another neurotoxic substance, such as glutamate, to cause neurotoxicity. Then, the addition of sublevels of viral or cellular toxins might result in neuronal injury ${ }^{17,26-28}$.

\section{The CNS as a sanctuary for HIV-1 infection}

The main purpose of the treatment based on a combination of ARV is to suppress HIV replication in all cellular compartments or tissues ${ }^{29}$. The CNS deserves special attention. The effective treatment of neurocognitive disorders related to HIV is more likely to depend on the complete suppression of HIV replication in the CNS. When complete suppression of HIV replication in the CNS does not occur, because ARV does not reach the CNS, the development of resistance to the ARV or for mutations in the virus is facilitated. Both result in situations that enable the viral particles to re-disperse into the CNS tissue. Thus, the CNS has been considered a possible reservoir or sanctuary for HIV ${ }^{21}$.

High-resolution phylogenetic analysis confirmed previous studies that showed a significant degree of compartmentalization in HIV subpopulations in the brain and peripheral tissue. The mixing between the HIV-1 subpopulations was evident, especially in patients that died from pathologies other than HIV-associated dementia. HIV-1 is clearly capable of migrating out of the brain, the meninges are the most likely primary transport tissues, and infected brain macrophages comprise an important HIV reservoir during highly active antiretroviral therapy (HAART) ${ }^{30}$.
Viral replication and its evolution inside CNS lead to a mutational adaptation to neuronal tissues. Phylogenetic analyses reveal different subpopulations in blood and CNS compartments. Genetics variants adapted to CNS can be the bases to some neurocognitive dysfunctions ${ }^{31}$.

The viral particles in CSF may have different origins: they can drain through CSF perivascular spaces, be produced by infected cells in meninges and cross the plasma during the production of CSF by the choroid plexus, particularly if there is damage or inflammation of choroid plexus ${ }^{32}$.

\section{HIV-associated cognitive impairment}

HIV dementia is the most common preventable and treatable cause of neurocognitive impairment in individuals under 50 years old. The American Academy of Neurology and the World Health Organization recommend the terms "HIV-associated dementia" and "HIV-1 associated minor cognitive-motor complex" to designate the major and minor forms of cognitive impairment in HIV infection ${ }^{33}$. The latter does not involve impairment in daily activities. These criteria were reviewed in $2005^{34}$ (Table 1).

The frequency of neurocognitive impairment in recent studies, in the post HAART era in AIDS patients is $36 \%{ }^{35}$. In a prospective study with 1,555 participants from six USA centers, cognitive impairment was found in 39\%, including those in ARV therapy, without significant co-morbidities ${ }^{36}$.

In adults, $3 \%$ of the AIDS cases present with dementia as the first defining AIDS illness. More typically, the dementia is initiated through substantial immune deficiency and other defining systemic opportunist complications of AIDS.

Early in the HIV epidemic, dementia was a common sequel of advanced disease, affecting more than $50 \%$ of terminally ill patients. Subsequently, widespread treatment with zidovudine (AZT) reduced the incidence of HAD dramatically ${ }^{37}$. With the later introduction of a combination therapy and PI-based HAART, further improvement was seen ${ }^{29}$. The incidence of most HIV-related opportunistic infections, including those affecting

Table 1. Criteria for classification of neurocognitive impairment related with HIV³.

\begin{tabular}{|c|c|c|}
\hline & $\begin{array}{l}\text { Functional decline }^{1} \\
\text { reported or demonstrated }\end{array}$ & NP impairment ${ }^{1,5}$ \\
\hline Assimptomatic neurocognitive impairment & No & In $\geq 2$ cognitive domains \\
\hline Mild meurocognitive disorder & Mild & At least mild ${ }^{2}$ involving $\geq 2$ cognitive domains \\
\hline HIV associated dementia & Major & $\geq$ Moderate NP impairment ${ }^{3}$ on $>2$ cognitive domains ${ }^{4}$ \\
\hline
\end{tabular}

${ }^{1}$ Not explained by confounding conditions: opportunistic CNS disease, systemic illness, psychiatric illness, substance use or medications with CNS effects; ${ }^{2}>1$ SD below a demographically appropriate normative mean; ${ }^{3}>2$ SD below a demographically appropriate normative mean; ${ }^{4} A$ lternativamente, one domain could be more severely impaired ( $>2.5$ SD below the mean) and another less severely impaired (>1 SD below the mean); ${ }^{5}$ Neuropsychological (NP) testing or Mental Status Exam, when NP is not available. 
the CNS, dropped markedly. Thanks to changes in diagnosis and clinical management, HIV/AIDS, which was once an almost always fatal disease, has become, at least in those countries where ARV are available, a chronic disease requiring long term care. The survival rate has greatly improved for patients with dementia ${ }^{38}$. More recently, the appearance of dementia in persons whose CD4 counts have rebounded with ARV, and the relative increase of dementia as a percentage of AIDS-defining opportunistic illnesses ${ }^{29}$ has suggested that the CNS is not being treated as effectively as the lymphatic tissues.

Persistent neurocognitive deficit could be imputed to HIV chronic infection in the CNS; irreversible previous brain lesion, ARV therapy that fails to eradicate infection; continuous inflammatory reaction interfering with brain function ${ }^{39}$.

The last factor can be proved by the determination of CSF neopterin. This biomarker indicates macrophage activation in the groups who have undergone successful ARV therapy and in the group on HAART, with the CSF levels of neopterin being higher than the control group without HIV, indicating chronic macrophage activation ${ }^{40}$. The non-penetration of ARV in the $\mathrm{CNS}^{41}$ contributes to the persistent neurocognitive deficit, by allowing slow viral replication in the CNS. The improvement in neurocognitive performance after 12 weeks of HAART is higher among those receiving ARV with better penetration ${ }^{42}$.

In the HAART era, the prevalence of neurocognitive impairment has shifted towards a milder clinical presentation. Such mild clinical presentations can escape detection without formal neurological assessment and neuropsychological testing ${ }^{34}$. Short term outcomes include significant impact on independence in all aspects of daily life, including employment ${ }^{43}$, and perhaps most importantly, medication adherence ${ }^{44}$.

HIV encephalitis is characterized by a number of individually nonspecific neuropathological features (white matter pallor, microglial nodules, multinucleated giant cells, and gliosis). However, when they occur as a constellation in the setting of known HIV infection, they produce a characteristic neuropathological signature. The pathological findings are typically mild, even in cases where dementia is severe. Furthermore, encephalitis is neither a necessary nor sufficient cause for dementia. Thus, although both frequently coexist, each one of them may occur without the other. Immunocytochemical staining using antibodies directed against the HIV envelope protein gp41 is helpful in delineating the extent of brain infection. Some degree of neuronal loss can be demonstrated, but this correlates only modestly with cognitive status. Instead, severe damage to dendrites and synapses is readily evident. The scarcity of infected cells and the imprecise correlation between the severity of pa- thology and the degree of dementia indicates that host factors are likely to play a role in neuropathogenesis. Alterations in the balance of cytokines, neurotrophic factors, and neurotoxins, including glutamate receptor active compounds, have been found. An important question that remains unanswered is why some patients with HIV infection develop dementia while others don't.

The expression of adhesion molecules facilitates leukocyte traffic in the CNS. This infiltrate contributes to the production of cytokines, chemokines and neurotoxic factors, resulting in brain damage ${ }^{45}$.

Chemokines and its receptors have a central role in the interactions between HIV and the host. In the normal host, chemokines regulate immunological functions, such as chemotaxis, cellular activation and the expression of receptors. Chemokine receptors allow HIV to enter and infect susceptible cells and their deregulation contributes to the immunological loss that occurs in AIDS. Finally, because chemokine receptors are present in neurons and glia, potentially transmitting signals between brain cells, they can either directly or indirectly produce neuronal damage ${ }^{46}$.

Abundant presence of monocytes and macrophages in brain has greater correlation with HAD than the presence or extension of the HIV infection in brain ${ }^{47}$. Neurocognitive damage is not related with the viral infection level in CNS, but with inflammation level ${ }^{48}$.

Non-infected monocyte migration through endothelial junctions is regulated by several junction proteins such as the endothelial platelet adhesion cellular molecule (PECAM-1) ${ }^{49}$.

Besides extensive monocyte/macrophage infiltration, HAD pathogeneses also involve astroglioses and giant multinuclear cells, astrocyte dysfunction and apoptosis. Apoptosis is associated with HAD rate and progression. Infected macrophages influence in non-infected astrocytes apoptosis. These cells show important neuroprotective functions, like decrease in neurotoxin and excitatory amino acids level and BBB maintenance ${ }^{50}$.

The diagnoses of HAD and milder cognitive impairment are made by clinical criteria, after exclusion of other potential causes (Table 2). No single laboratory test establishes the diagnosis, but ancillary studies are useful for supporting or refuting the diagnosis ${ }^{51,52}$. Table 3 lists clinical signs and symptoms ${ }^{51}$. Neuropsychological evaluation is particularly helpful in cases of mild or moderate impairment.

\section{Tat protein}

Some HIV proteins (Fig 2) cause neuronal injury, as observed in patients with HAD: gp120, gp41, vpr, tat. Transient exposure to these virotoxins can trigger a cascade of events that eventually results in neuronal 
Table 2. HIV dementia diagnostic criteria.

\begin{tabular}{l} 
Seropositivity to HIV (confirmed by Western-blot) \\
History of progressive alterations in cognition and behavior \\
Demonstrated impairment in at least two domains of neuropsy- \\
chological performance \\
Absence of \\
Focal signs on neurologic examination \\
Intoxication or withdrawal (alcohol or other substance) \\
Metabolic disturbance \\
CNS opportunistic infection or neoplastic lesions \\
\hline
\end{tabular}

A

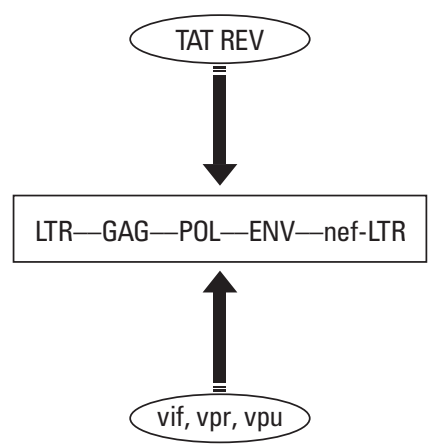

Table 3. Clinical signs and symptoms of HIV dementia.

\begin{tabular}{|c|c|c|}
\hline & Symptoms & Signs \\
\hline \multirow[t]{2}{*}{ Cognitive } & Poor concentration & Slowness of thought \\
\hline & Forgetfulness & $\begin{array}{l}\text { Executive cognitive } \\
\text { dysfunction }\end{array}$ \\
\hline \multirow[t]{2}{*}{ Motor } & Gait instability & $\begin{array}{l}\text { Saccadic ocular } \\
\text { pursuit movements }\end{array}$ \\
\hline & $\begin{array}{l}\text { Urinary urgency/ } \\
\text { hesitation }\end{array}$ & $\begin{array}{l}\text { Slowing of repetitive } \\
\text { movements }\end{array}$ \\
\hline Behavior & $\begin{array}{l}\text { Loss of interest in } \\
\text { friends, hobbies }\end{array}$ & Apathy \\
\hline
\end{tabular}

B

Fig 2. [A] The HIV genome structure consists of the typical retroviral LTR-GAG-POL-ENV-LTR structure, and the reguratory long terminal repeat (LTR) the genes for structural (GAG or group specific antigen), polymerase (POL) and envelope (ENV) proteins along with accessory genes (tat, vpr, vpu, nef). [B] Main HIV-1 proteins codified by virus genes.

damage. Virotoxins are able to increase their potential toxicity by interacting with non-infected cells, damaging non-adjacent $\operatorname{sites}^{53}$. One of the main proteins related to HIV associated neuronal damage is tat. Its activity is necessary to viral replication ${ }^{53}$.

Tat is the only protein actively secreted by HIV-1 infected cells by means of an energy dependent process. It circulates in the blood at high levels during HIV infection and can cross BBB, and large quantities of this protein enter the CNS. Tat can depolarize neurons through direct interaction with the membranes of these cells, can act like substrate to adhesion and induce aggregation of neural cultures ${ }^{53}$.

Tat protein easily penetrates different cellular types and contributes to HIV transactivation in infected cells. It specifically interacts with the vascular endothelial growth factor (VEGF) and its connection to these surface molecules activates several protein kinases. Protein kinase $C$ is a signal molecule that mediates tat effects in microvascular endothelium, which impacts endothelial cell proliferation and migration ${ }^{54}$.

As soon as tat is secreted by infected cells, it is picked up by cells causing cytoplasmic and nuclear events, like alteration in gene transcription, cytokine and chemokine secretion, receptor activation and expression of apoptotic $\operatorname{protein}^{48}$.

Tat has a strong monocyte chemotactic property. It acts like a chemokine itself and/or indirectly through monocyte chemotactic protein 1 (MCP-1) currently classified as CCL2- secreted by astrocytes, the most numerous cells in the central nervous system and that are in close contact with $\mathrm{BBB}^{13}$.

Some HAD patients show peroxynitrite formation in perivascular areas in brain tissue that can lead to neuronal injury, affecting BBB integrity, increasing brain endothelial cells permeability. Peroxynitrite interferes with protein phosphorylation. Kinase phosphorylation is essential for tight junction membrane assembly and interference with this phosphorylation may result in its rupture ${ }^{55}$.

A little amount of infiltrate monocytes can trigger a cascade of events, leading to immune activation, oxidative stress, decrease in intracellular glutathione (responsible for redox status maintenance and antioxidant protection of endothelial cells), barrier breakdown and great monocyte influx that together can result in neurological damage progression ${ }^{55-57}$.

Tat is internalized by neurons by to low-density lipoprotein recepto-related protein (LRP) receptor expressed 
on cellular surface. For the occurrence of neuronal apoptosis, tat must bind to LRP and N-methyl-D-aspartate (NMDAR) receptor. Apoptosis cascade starts in neurons that express these receptors and spread to neurons that do not express these receptors and to astrocytes. NMDAR subunits are phosphorylated when tat potentiates glutamate excitotoxicity in a protein kinase $\mathrm{C}$ and tyrosine kinase dependent manner ${ }^{48}$.

Besides apoptosis, mitochondrial disorders, cytochrome c release, calcium excess and caspase 3 cascade activation also occur in neurons. Extracellular tat induces depolarization and intracellular calcium elevation in neurons, which could be responsible for neuronal death ${ }^{56}$.

Two alterations that apparently contribute to the apoptosis process are: increase in oxygen reactive species production and break of calcium homeostasis. The increase in cytoplasmic calcium level leads to the production of several oxygen reactive species, including super oxide, hydrogen peroxide nitric oxide and peroxynitrite, molecules that may damage mitochondrial membrane and DNA ${ }^{56}$.

Tat induces TNF- $\alpha$ release by macrophages and it has an important role in HIV infection pathogeneses. TNF- $\alpha$ is a mediator of CNS inflammatory events. It activates microglia cells, monocytes and macrophages. It is a potent inductor of inflammatory response and can stimulate an increase in CCL2, inflammatory cytokines, ICAM-1, VCAM-1 expression. Also, it can act like a chemoattractant factor, though its chemotactic response is smaller than CCL2 $2^{57}$.

Nuclear factor (NF-kB) is a transcriptional factor that activates many viral and cellular promoters and has binding places to cytokine promoters. Moreover, it regulates adhesion molecules, chemokine and cytokine expression. TNF- $\alpha$ induces NF- $\mathrm{kB}$ translocation to the nucleus increasing inflammatory cytokine expression in astrocytes. NF- $\mathrm{kB}$ may influence CCL2 expression directly. This bind is generally associated with protein kinase activation ${ }^{58}$.

Tat chronic production in brain causes significant alteration in inflammation histological markers and in the infected individual's behavior ${ }^{59}$.

\section{Protein Btat versus Ctat}

HAD prevalence between asymptomatic individuals in USA and Europe is around 15 to $30 \%$. There was a low HAD incidence in India around 1.4\%, although this was not related with underdiagnosis ${ }^{13}$, indicating that could be related with subtype. In India and in underdeveloped countries, subtype $\mathrm{C}$ is the most prevalent. In USA and Europe, the prevalent subtype is B. Thus, it is important to identify biological and genetic differences between viral subtypes that act like bases to explain this HAD prevalence difference ${ }^{13}$.
Subtype C can exhibit reduced neuroinvasiveness, possibly due to a different protein tat primary conformation. Non-C subtypes protein tat are conserved to preserve a dicysteine-containing motif (30 and 31 positions), necessary to monocyte migration. HIV subtype $C$ shows a replacement of cysteine with serine, thus breaking dicysteine motif and reducing monocyte attraction ability. More than $99 \%$ of non C subtypes present cysteine in 31 position and around $90 \%$ of subtype $C$ sequences present a serine in this position ${ }^{13}$.

Some differences between subtype B tat and subtype C-tat are observed. B-tat caused greater neuronal apoptosis compared to subtype C. C-tat caused lower oxidative stress in neurons. B-tat is more flexible than C-tat, which can explain its greater biological activity ${ }^{60}$.

When CCL2 binds to CCR2, an increase in arachidonic acid release, extracellular calcium influx and chemotaxis occurs. A mutation in CCF sequence to SSG annuls the ability to induct calcium influx, resulting in the failure of tat protein binding to CCR2, decrease in chemotactic activity and in the ability to induce inflammatory mediators, like IL-6, CCL2 and TNF- $\alpha^{47}$.

Although cognitive disorders are less severe, they are present in individuals with HIV subtype C, suggesting that subtype $\mathrm{C}$ also lead to cognitive impairment associated to HIV. Otherwise, a functional variation in tat may provide some protection, although subtle, in individuals with subtype $C^{61}$.

\section{Interactions of other HIV proteins and neuronal function}

Viral envelop protein gp120 interacts with neurons and can lead to neuronal death. Gp41 can induce MMPs activity in neuronal culture. In addition, it stimulates the release of glutamate from astrocytes. Vpr has viral transcription regulatory function. Elevated vpr level is found in CSF of HAD patients. This protein induces neuron apoptosis by caspase via activation ${ }^{62}$.

Other proteins, like nef and rev, have a role in BBB rupture, inducing neurotoxicity ${ }^{53}$.

CCL2 is a low-weight chemokine expressed not only by astrocytes, but also by immune, endothelial and neural cells. It is responsible for monocytes, lymphocytes $\mathrm{T}$ and natural killer recruitment to inflammation areas, promoting cellular adhesion and transmigration trough BBB. This protein accumulates in the CSF of HAD patients and its level correlates with the degree of dementia ${ }^{13}$.

Higher levels of CCL2 in CSF, compared to blood, unlike viral load levels, suggest that, in CNS, HIV replication can be related to CCL2 local expression. CNS cells are considered the major source of plasma CCL2, because astrocytes, microglia and endothelial cells produce CCL2, and this molecule has low molecular weight and 
its diffusion through intact $\mathrm{BBB}$ can occur through a concentration gradient. This also explains why CCL2 levels are higher in CSF than in plasma, because these molecules are diluted due the significant plasmatic volume ${ }^{63}$.

The relationship between CCL2 level and viral load in CSF suggests that it is co-regulated or that one is a potent stimulus to the other. CCL2 probably regulates CSF viral load because changes in CCL2 levels occurred before or concomitantly to changes in CSF viral load ${ }^{63}$.

HIV viral load increase in the CNS involves recruitment of resident cells, like astrocytes and microglia cells, leukocyte infiltration, and active infection. CCL2 has an important role in the recruitment of non-infected cells to other CNS regions, resulting in dispersion inside the CNS. Resident cell infection leads to a chronic inflammatory response that may contribute to CNS damage ${ }^{64}$.

\section{REFERENCES}

1. Loureiro R, Blank D, Wortmann AR, Rosa T, Morgado M. Prevalência e fatores de risco associados ao Subtipo $\mathrm{C}$ do HIV-1 em pacientes soropositivos em acompanhamento no Ambulatório de Dermatologia Sanitária da Secretaria da Saúde do RGS. Boletim da Saúde 2002;16:82-90.

2. Ariën KK, Vanham G, Arts EJ. Is HIV-1 evolving to a less virulent form in humans? Nat Rev 2007;5:141-151.

3. FIOCRUZ identifica ocorrência de casos de coinfecção por HIV-1 e HIV-2 no Brasil. Newslab 2010;12:10.

4. Torian LV, Eavey JJ, Punsalang AP, et al. HIV type 2 in New York City, 20002008. Clin Infect Dis 2010;51:1334-1342.

5. Thomson MM, Nájera R. Molecular epidemiology of HIV-1 variants in the global AIDS pandemic: an update. AIDS Rev 2005;7:210-224.

6. Taylor BS, Sobieszczyk ME, McCutchan FE, Hammer SM. The challenge of HIV-1 subtype diversity. New Engl J Med 2008;358:1590-1602.

7. Plantier JC, Leoz M, Dickerson JE, et al. A new human immunodeficiency virus derived from gorillas. Nat Med 2009;15:871-872.

8. Calef C, Mokili J, O'Connor DH, Watkins DI, Korber B. Numbering positions in SIV relative to SIVMM239 (revised*). HIV sequence database. Available at http://www.hiv.lanl.gov/content/sequence/HIV/REVIEWS/SIV_NUMBERING2001/SivNumbering.html (accessed 02/18/2011)

9. Raboni SM, Almeida SM, Rotta I, et al. Molecular epidemiology of HIV-1 clades in Southern Brazil. Mem Inst Oswaldo Cruz 2010;10:1044-1049.

10. Bello G, Passaes CPB, Guimarães ML, et al. Origin and evolutionary history of HIV-1 subtype C in Brazil. AIDS 2008;22:1993-2000.

11. Fontella R, Soares MA, Schrago CG. On the origin of HIV-1 subtype $C$ in South America. AIDS 2008;22:2001-2011.

12. Carr JK, Avila M, Carrillo MG, et al. Diverse BF recombinants have spread widely since the introduction of HIV-1 into South America. AIDS 2001; 15: 41-47.

13. Ranga U, Shankarappa R, Siddapa NB, et al. Tat protein of human immunodeficiency virus type 1 subtype $C$ strains is a defective chemokine. J Virology 2004;78:2586-2590.

14. Resnick L, Berger JR, Shapshak P, Tourtellotte WW. Early penetration of the blood brain barrier by HIV. Neurology 1988;38:9-14.

15. Marshall DW, Brey RL, Cahill WT, Houk RW, Zajac RA, Boswell RN. Spectrum of cerebrospinal fluid in various stages of human immunodeficiency virus infection. Arch Neurol 1988;45:954-958.

16. Carne CA, Tedder RS, Smith A, et al. Acute encephalopathy coincident with seroconversion for anti- HTLV-III. Lancet 1985;2:1206-1208.

17. Gendelman HE, Lipton SA, Epstein L, Swindells S. The neurology of AIDS. New York: Chapman \& Hall, 1998.

18. Price RW. The two faces of HIV infection of cerebrospinal fluid. Trends Microbiol 2000;8:387-390.
19. Brew BJ, Wesselingh SL, Gonzales M, Heyes MP, Price RW. How HIV leads to neurological disease. Med J Australia 1996;164:233-234.

20. Cross AK, Woodroofe MN. Chemokine modulation of matrix metalloproteinases and TIMP production in adult rat brain microglia and a human microglial cell line in vitro. Glia 1999;28:183-189.

21. Wong JK, Günthard HF, Ellis RJ, et al. The development and trafficking of multi-drug resistant HIV in plasma and CSF during the failure of combination antiviral therapy. Antivir Ther 1999:4:76-77.

22. Gabuzda D, He J, Ohagen A, Vallat AV. Chemokine receptors in HIV-1 infection of the central nervous system. Semin Immunol 1998;10:203-213.

23. Hicks A, Potula R, Sui YJ, et al. Neuropathogenesis of lentiviral infection in macaques: roles of CXCR4 and CCR5 viruses and interleukin-4 in enhancing monocyte chemoattractant protein-1 production in macrophages. Am J Pathol 2002;161:813-822.

24. Tyler KL, McArthur JC. Through a glass, darkly: cerebrospinal fluid viral load measurements and the pathogenesis of human immunodeficiency virus infection of the central nervous system. Arch Neurol 2002;59:909-912.

25. Glass JD, Wesslingh SL. Viral load in HIV-associated dementia. Ann Neurol 1998;44:150-151.

26. Nath A. Pathobiology of human immunodeficiency virus dementia. Semin Neurol 1999;19:113-127.

27. Patel CA, Mukhtar M, Pomerantz RJ. Human immunodeficiency virus type 1 vpr induces apoptosis in human neuronal cells. J Virol 2000;74:9717-9726.

28. Power C, Kong PA, Crawford TO, et al. Cerebral white matter changes in Acquired immunideficiency syndrome dementia: alterations of the blood brain barrier. Ann Neurol 1993;34:339-350.

29. Dore GJ, Correll PK, Li Y, Kaldor JM, Cooper DA, Brew BJ. Changes to AIDS dementia complex in the era of highly active antiretroviral therapy. AIDS 1999;13:1249-1253.

30. Lamers SL, Gray RR, Salemi M, Huysentruyt LC, McGrath MS. HIV-1 phylogenetic analysis shows HIV-1 transits through the meninges to brain and peripheral tissues. Infect Genet Evolution 2011;11:31-37.

31. Smith DM, Zárate $\mathrm{S}$, Shao H, et al. Pleocytosis is associated with disruption of HIV compartmentalization between blood and cerebral spinal fluid viral populations. Virology 2009;385:204-208.

32. Zink MC, Clements JE. The two faces of HIV infection of cerebrospinal fluid: response. Trends Microbiol 2000;8:390-391.

33. McArthur JC, Hoover DR, Bacellar MA, et al. Dementia in AIDS patients: incidence and risk factors. Multicenter AIDS Cohort Study (MACS). Neurology 1993;43:2245-2252.

34. Antinori A, Arendt G, Becker JT, et al. Updated research nosology for HIVassociated neurocognitive disorders. Neurology 2007;69:1789-1799.

35. Heaton RK, Cysique LA, Jin H, Shi C, Yu X, Letendre S. Neurobehavioral effects of human immunodeficiency virus infection among former plasma donors in rural China. J Neurovirol 2008;14:536-549.

36. Heaton RK, Clifford DB, Franklin DRJ, et al. HIV-associated neurocognitive disorders persist in the era of potent antiretroviral therapy: CHARTER Study. Neurology 2010;75:2087-2096.

37. Portegies P, de Gans J, Lange JM, et al. Declining incidence of AIDS dementia complex after introduction of zidovudine treatment. British Med J 1989;299:819-821.

38. Dore GJ, Cooper DA, Pozniak AL, et al. Eficacy of tenofovir disoproxil fumarate in antiretroviral therapy naïve and experienced patients coinfected with HIV-1 and Hepatitis B Virus. J Infect Dis 2004;189:1185-1192.

39. Ellis R. HIV and antiretroviral therapy: impact on the central nervous system. Prog Neurobiol. 2010;91:185-187

40. Hagberg $L$, Cinque $P$, Gisslen $M$, et al. Cerebrospinal fluid neopterin: an informative biomarker of central nervous system immune activation in HIV-1 infection. AIDS Res Ther 2010; 3:15.

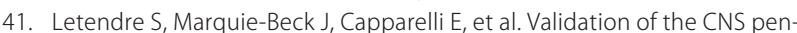
etration-effectiveness rank for quantifying antiretroviral penetration into the central nervous system. Arch Neurol 2008;65:65-70.

42. Cysique LA, Vaida F, Letendre $S$, et al. Dynamics of cognitive change in impaired HIV-positive patients initiating antiretroviral therapy. Neurology 2009;73:342-348.

43. Heaton RK, Marcotte TD, Mindt MR, et al. The impact of HIV-associated neuropsychological impairment on everyday functioning. J Int Neuropsychol Soc 2004;10:317-331.

44. Cysique LA, Murray JM, Dunbar M, Jeyakumar V, Brew BJ. A screening algorithm for HIV-associated neurocognitive disorders. HIV Med 2010;11: 642-649.

45. Woodman SE, Benveniste EN, Nath A, Berman JW. Human immunodefi- 
ciency virus type 1 Tat protein induces adhesion molecule expression in astrocytes. J Neurovirol 1999;5:678-684.

46. Karpus WJ. Chemokines and central nervous system disorders. J Neurovirol 2001;7:493-500

47. Campbell GR, Watkins JD, Singh KK, Loret EP, Spector SA. Human Immunodeficiency virus type 1 subtype $C$ Tat fails to induce intracellular calcium flux and induces reduced tumor necrosis factor production from monocytes. J Virology 2007:81:5919-5928.

48. King JE, Eugenin EA, Buckner CM, Berman JW. HIV Tat and neurotoxicity. Microb Infect 2006;8:1347-1357.

49. Kim TA, Avraham HK, Koh YH, Jiang S, Park IW, Avraham S. HIV-1 Tat-mediated apoptosis in human brain microvascular endothelial cells. J Immunol 2003; 170:2629-2637.

50. Weiss JM, Nath A, Major EO, Berman JW. HIV-1 Tat induces monocyte chemoattractant protein-1-mediated monocyte transmigration across a model of the human blood-brain barrier and up-regulates CCR5 expression on human monocytes. J Immunol 1999;163:2953-2959.

51. Harrison MJG. Guidelines for management of HIV associated dementia, myelopathy, neuropathy and myopathy. Int J STD AIDS 1998;9:390-393.

52. Power C, Selnes OA, Grim JA, McArthur JC. HIV dementia scale: a rapid screening test. J Acquir Immune Defic Syndr Hum Retrovirol 1995;8:273-278.

53. Nath A. Human immunodeficiency virus (HIV) proteins in neuropathogenesis of HIV dementia. J Infect Dis 2002;186(Suppl):S193-S198.

54. Park IW, Wang JF, Groopman JE. HIV-1 Tat promotes monocyte chemoattractant protein-1 secretion followed by transmigration of monocytes. Blood J 2001;97:352-358.

55. Boven LA, Middel J, Verhoef J, De Grott CJA, Nottet HSLM. Monocyte infiltration is highly associated with loss of tight junction protein zonula occludens in HIV-1 associated dementia. Neuropath Appl Neuro 2000; 26:356-360.

56. Kruman II, Nath A, Mattson MP. HIV-1 protein Tat induces apoptosis of hip- pocampal neurons by a mechanism involving caspase activation, calcium overload, and oxidative stress. Exp Neurol 1998;154:276-288.

57. Pu H, Tian J, Flora G, et al. HIV-1 Tat protein upregulates inflammatory mediators and induces monocyte invasion into the brain. Mol Cell Neurosci 2003;24:224-237.

58. Brabers NACH, Nottet HSLM. Role of the pro-inflammatory cytokines TNF-alpha and IL-beta in HIV-associated dementia. Eur J Clin Investig 2006:36:447-458

59. Bruce-Keller AJ, Chauhan A, Dilmayuga FO, Gee J, Keller JN, Nath A. Synaptic transport of human immunodeficiency virus-Tat protein causes neurotoxicity and gliosis in rat brain. J Neurosci 2003;23:8417-8422.

60. Mishra M, Vetrivel S, Siddappa NB, Ranga U, Seth P. Clade-specific differences in neurotoxicity of human immunodeficiency virus-1 B and C Tat of human neurons: significance of dicysteine C30C31 motif. Ann Neurol 2008;62:366-376

61. Yepthomi T, Paul R, Vallabhaneni S, et al. Neurocognitive consequences of HIV in Southern India: a preliminary study of clade C virus. J Int Neuropsychol Soc 2006;12:424-430.

62. Van de Bovenkamp M, Nottet HSLM, Pereira CF. Interactions of human immunodeficiency virus-1 proteins with neurons: possible role in the development of human immunodeficiency virus-1-associated dementia. Eur J Clin Investig 2002;32:619-627.

63. de Almeida SM, Letendre S, Zimmerman J, Lazzaretto D, MsCutchan A, Ellis R. Dynamics of monocyte chemoattractant protein type one (MCP-1) and HIV viral load in human cerebrospinal fluid and plasma. J Neuroimmunol 2005;169:144-152.

64. Eugenin EA, Osiecki K, Lopez L, Goldstein H, Calderon TM, Berman JW. CCL2/monocyte chemoattractant protein-1 mediates enhanced transmigration of human immunodeficiency virus (HIV)-infected leukocytes across the blood-brain barrier: a potential mechanism of HIV-CNS invasion and NeuroAIDS. J Neurosci 2006:26:1098-1106. 